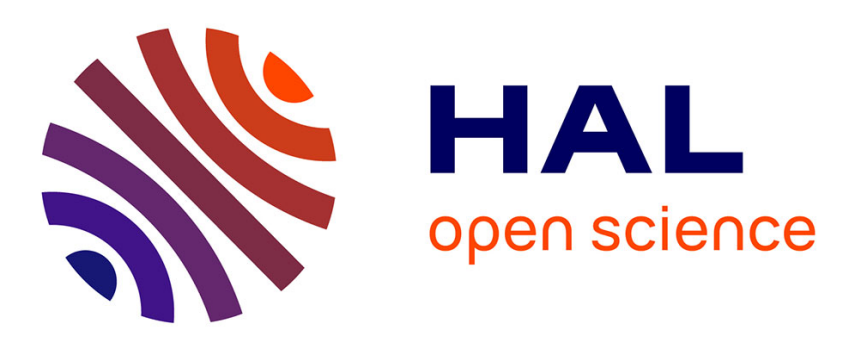

\title{
Synthesis of tetrahedral patchy nanoparticles with controlled patch size
}

Pierre-Etienne Rouet, Rawan Khalaf, Stéphanie Exiga, Etienne Duguet, Serge Ravaine

\section{- To cite this version:}

Pierre-Etienne Rouet, Rawan Khalaf, Stéphanie Exiga, Etienne Duguet, Serge Ravaine. Synthesis of tetrahedral patchy nanoparticles with controlled patch size. Journal of Nanoparticle Research, 2020, 22 (10), 10.1007/s11051-020-05060-w . hal-02986056

\section{HAL Id: hal-02986056 https://hal.science/hal-02986056}

Submitted on 2 Nov 2020

HAL is a multi-disciplinary open access archive for the deposit and dissemination of scientific research documents, whether they are published or not. The documents may come from teaching and research institutions in France or abroad, or from public or private research centers.
L'archive ouverte pluridisciplinaire HAL, est destinée au dépôt et à la diffusion de documents scientifiques de niveau recherche, publiés ou non, émanant des établissements d'enseignement et de recherche français ou étrangers, des laboratoires publics ou privés. 


\title{
Synthesis of tetrahedral patchy nanoparticles with controlled patch size
}

\author{
Pierre-Etienne Rouet, ${ }^{1,2}$ Rawan Khalaf, ${ }^{1}$ Stéphanie Exiga, ${ }^{1}$ Etienne Duguet $^{2}$ and Serge Ravaine $*^{1}$ \\ ${ }^{1}$ Univ. Bordeaux, CNRS, CRPP, UMR 5031, 33600 Pessac, France \\ ${ }^{2}$ Univ. Bordeaux, CNRS, ICMCB, UMR 5026, 33600 Pessac, France
}

*To whom correspondence should be addressed: serge.ravaine@crpp.cnrs.fr

ORCID identification number: 0000-0002-6343-8793

Keywords: patchy nanoparticles, tetrahedral, patch size

\begin{abstract}
Silica nanoparticles with four circular surface patches made of polystyrene (PS) and arranged in a tetrahedral symmetry are synthesized through the multi-step growth of the silica core of silica/PS tetrapods. Transmission electron microscopy and energy dispersive X-Ray analysis studies indicate that, as the silica core regrows, its surface conforms to the shape of the polystyrene nodules, allowing good control of the size of the emerged fraction of these. Patches with an angular width as small as $49^{\circ}$ were achieved, which is a prerequisite for their assembly in the form of a diamond crystal phase.
\end{abstract}

\section{Introduction}

In recent decades, the development of functional and programmable materials via the self-assembly of colloidal particles has become a major challenge, which could ultimately compete with additive manufacturing technologies. One famous example is the fabrication of colloidal crystals from sub-micrometer, mostly spherical, particles suspended in a colloidal solution, which have important technological applications such as photonic 
crystals [1,2], optical filters [3], optical sensors [4] and non-bleachable color materials [5]. In order to form more complex colloidal structures, it has been shown that the shape anisotropy of the particles, their size ratio or their antagonistic interactions (essentially ionic) are parameters on which it is possible to play. Shevchenko et al. have for instance shown that by mixing two types of colloidal atoms with opposite surface charges and different sizes, crystal structures similar to those of $\mathrm{NaCl}, \mathrm{AlB}_{2}, \mathrm{MgZn}_{2}, \mathrm{CaB}_{6}$ or $\mathrm{NaZn}_{13}$ are obtained [6]. Motivated by previous studies that showed that diamond and other percolating open dielectric lattices possess a full omnidirectional photonic bandgap at optical frequencies [7-9], Ducrot et al. fabricated diamond and pyrochlore structures by the DNA-directed assembly of tetrahedral clusters and spheres [10]. Another envisaged strategy to realize a diamond structure by self-assembly is to use building blocks with four patches in a tetrahedral geometry [11]. Theoretical studies showed that this route is far to be straightforward $[12,13]$ but can lead to a diamond cubic crystal phase for a very narrow range of pressures when the opening angle $\theta$ of the patches is sufficiently narrow, ca. smaller than $28.7^{\circ}$ [14]. Many routes for the production of tetrahedral patchy particles have been reported [15-17]. For instance, Gong et al. produced particles with four liquid patches from hybrid liquid-solid clusters through the addition of a plasticizer [18]. Kraft et al. obtained particles with four patches through the assembly of polymer particles with a liquid protusion and the subsequent polymerization of the liquid [19]. The patch size could be determined by controlling the wetting angle between the liquid protrusion, the aqueous phase, and the polymer seed particles and by choosing the diameter of the latter ones.

Herein, an efficient way to synthesize tetrahedral patchy silica nanoparticles (NPs) with PS patches of controlled size is demonstrated. The strategy is based on the controlled enlargement of the silica core of binary tetrapods that have been synthesized by a seeded-growth emulsion polymerization reaction through successive cycles of tetraethoxysilane addition and removal of unreacted species. The morphology of the NPs after each cycle has been carefully characterized by transmission electron microscopy (TEM) and energy dispersive X-Ray analysis (EDX) mapping experiments, paying particular attention to estimating the value of the opening angle of the patches.

\section{Experimental details}

\section{Materials}

We used styrene (Sigma-Aldrich, 99\%), methacryloxymethyltriethoxysilane (MMS, ABCR, 98\%), sodium persulfate (Sigma-Aldrich, 99\%), Symperonic ${ }^{\circledR}$ NP30 (Aldrich), sodium dodecylsulfate (SDS, Sigma-Aldrich, > 90\%), tetraethoxysilane (TEOS, Sigma-Aldrich, 99\%), ammonia (28-30\% in water, SDS), as we received them. 
We systematically used ultrapure water with a resistivity of $18.2 \Omega \cdot \mathrm{cm}$ at $25^{\circ} \mathrm{C}$ obtained from a Milli-Q system

(Millipore). We purchased absolute ethanol from VWR Chemicals.

\section{Synthesis of the silica/PS tetrapod-like templates}

We prepared a batch of tetrapods, consisting of a central silica core surrounded by four PS satellite nodules, by seeded-growth emulsion polymerization of styrene, according to a procedure we published previously [20]. We used silica seeds with a diameter of $53 \pm 2 \mathrm{~nm}$, previously surface-modified with MMS (0.5 molecule.nm $\left.{ }^{-2}\right)$, a 95\%/5\% w/w surfactant mixture (3 g.L $\left.\mathrm{L}^{-1}\right)$ of Symperonic $\circledR$ NP30 and SDS, and sodium persulfate as initiator $\left(0.5 \% \mathrm{w} / \mathrm{w}\right.$ relative to monomer). The polymerization was performed at $70^{\circ} \mathrm{C}$ for $6 \mathrm{~h}$. The morphological yield in tetrapods was $76 \%$ and the average diameter of the PS satellites was $135 \pm 3 \mathrm{~nm}$.

\section{Controlled growth of the silica core}

$9.1 \mathrm{~mL}$ of absolute ethanol, $0.7 \mathrm{~mL}$ of ammonia and $0.2 \mathrm{~mL}$ of the dispersion of silica-polystyrene tetrapods were introduced into a $25 \mathrm{~mL}$ flask and the mixture was homogenized using a magnetic bar. In the one-step approach, $20 \mu \mathrm{L}, 200 \mu \mathrm{L}$ or $2 \mathrm{~mL}$ of TEOS were added all at once after 5 minutes. The reaction was left under stirring at $0{ }^{\circ} \mathrm{C}, 20{ }^{\circ} \mathrm{C}$ or $50{ }^{\circ} \mathrm{C}$ (see text) and a $50 \mu \mathrm{L}$ fraction of the mixture was taken every 5 minutes during one hour and then dispersed in $1 \mathrm{~mL}$ of absolute ethanol for TEM analysis. In the iterative approach, $200 \mu \mathrm{L}$ of TEOS were added all at once after 5 minutes. The reaction was left under stirring at $20{ }^{\circ} \mathrm{C}$ for 15 minutes. The reaction medium was poured into a $50 \mathrm{~mL}$ Falcon tube containing $15 \mathrm{~mL}$ of absolute ethanol. After 3 cycles of centrifugation (12,000 g / 5 minutes) and redispersion in absolute ethanol, the particles were finally redispersed in $10 \mathrm{~mL}$ of a previously prepared hydro-alcoholic solution (absolute ethanol/ammonia/water volume ratio: $91 \% / 7 \% / 2 \%)$. This protocol was renewed to obtain the next generation.

\section{Characterization techniques}

Transmission electron microscopy and energy dispersive X-Ray analysis mapping experiments were performed using a Hitachi H600 microscope operating at an acceleration voltage of $75 \mathrm{kV}$ and a JEOL JEM 1400 Plus microscope operating at $120 \mathrm{kV}$, respectively. We prepared the samples by depositing one drop of the colloidal dispersion on conventional carbon-coated copper grids. We let the liquid evaporate in the open air at room temperature and placed the grids in a box away from dust. 


\section{Results and discussion}

The first route we explored to fabricate silica NPs with four PS patches of controlled size was based on our previous studies $[21,22]$. Indeed, we have already shown that the addition of a small amount of tetraethoxysilane into a hydroalcoholic suspension of multipods, in presence of ammonia, led to the growth of the silica core conforming to the shape of the polystyrene nodules. We thus decided to follow this pathway by increasing the quantity of TEOS in order to encapsulate almost all of the PS nodules with silica. TEM images of Fig. 1 show that for a low volume of TEOS added $(20 \mu \mathrm{L})$, the morphology of tetrapods barely changed in one hour. The silica core grew slightly from $53 \pm 2 \mathrm{~nm}$ to $85 \pm 3 \mathrm{~nm}$. For a TEOS volume of $200 \mu \mathrm{L}$, the silica core diameter reached $208 \pm 4 \mathrm{~nm}$ after one hour but silica protuberances appeared on the polystyrene nodules after 20 minutes of reaction. Such silica bumps appeared after only 5 minutes and further grew with time when the added TEOS volume is ten times larger. The formation of these silica bumps can be explained by the migration of part of TEOS inside the PS nodules, which is realistic as long as it remains organophilic, that is to say slightly hydrolyzed. Above a certain concentration of TEOS in the PS nodules, TEOS molecules would be forced to polycondense in the form of excrescences on the surface of the nodules.

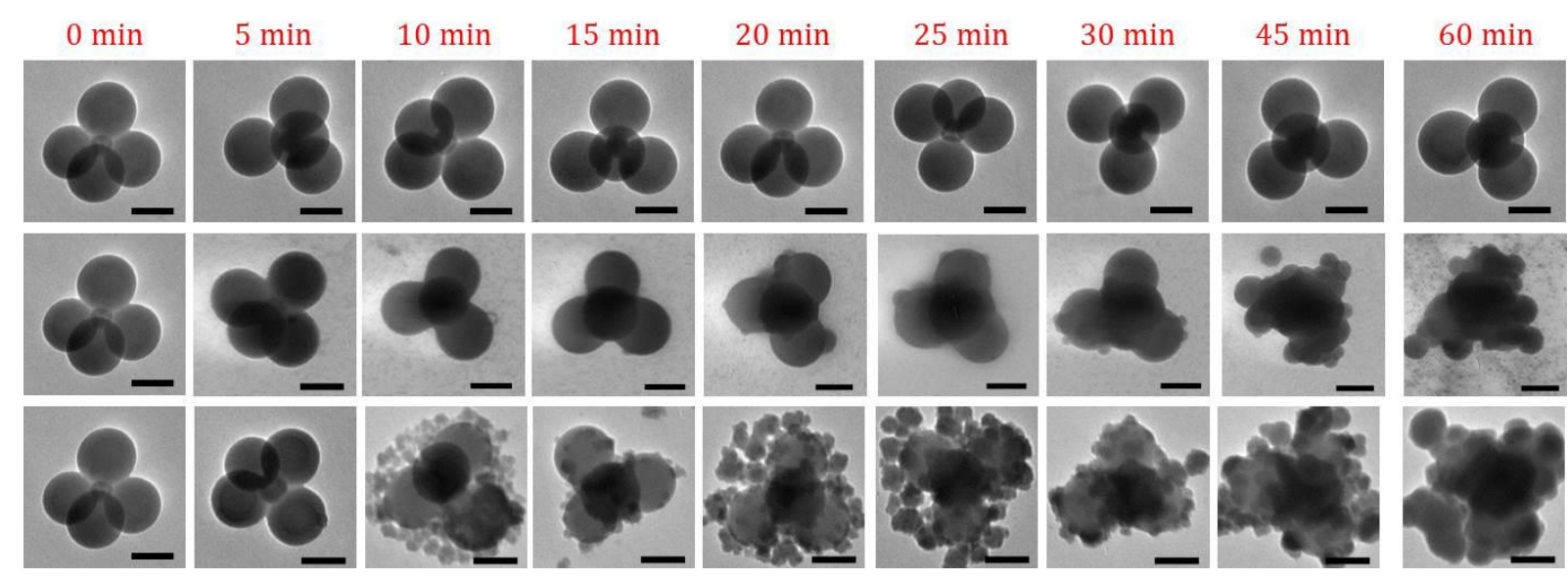

Fig.1 TEM image showing the morphological evolution of the tetrapods over time after adding different TEOS volumes at $20^{\circ} \mathrm{C}: 20 \mu \mathrm{L}$ (top), $200 \mu \mathrm{L}$ (b) and $2 \mathrm{~mL}$ (bottom). Scale bars: $100 \mathrm{~nm}$

We also studied the influence of temperature on the growth of the silica core. Fig. 2 shows that silica bumps only appeared after 45 minutes at $0{ }^{\circ} \mathrm{C}$, whereas they appeared as early as 10 minutes when the reaction was conducted at $50{ }^{\circ} \mathrm{C}$. The temperature thus accelerates the kinetics of the silica bumps formation, in agreement with the improvement of the polymerization of silane derivatives by using higher temperatures [23]. 


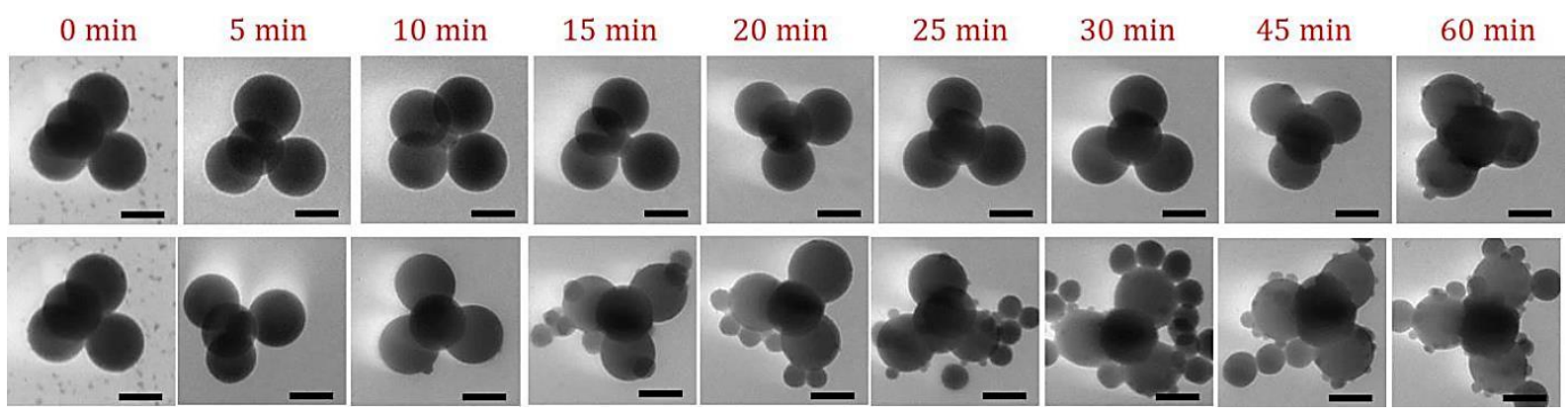

Fig.2 TEM image showing the morphological evolution of the tetrapods over time after adding $200 \mu \mathrm{L}$ of TEOS at $0^{\circ} \mathrm{C}$ (top) and $50^{\circ} \mathrm{C}$ (bottom). Scale bars: $100 \mathrm{~nm}$

As this first method did not make it possible to obtain silica NPs with four surface patches without the formation of undesired silica protuberances, we thus developed an alternative iterative route based on successive additions of a small amount of TEOS and centrifugation / redispersion cycles making it possible to eliminate the excess of unreacted TEOS or its hydrolyzed derivatives (Fig. 3(a)). In order to optimize the reaction time and to avoid the formation of silica bumps, we chose to work with 15 -minute sequences at $20^{\circ} \mathrm{C}$. TEM images of Fig. 3 (b) show the morphology of the tetrapods after a series of eight stages (Generations 1 to 8). It is noted that the silica core grew by strictly following the shape of the PS nodules and no silica bump formed on the surface of these. We have calculated morphological yields by statistical analysis of low-magnification TEM images (Fig. 3(c)) over about 100 clusters. Yields were equal to $66 \%, 58 \%, 62 \%$ and $60 \%$ for generation 2, 4, 6 and 8, respectively. The values of the opening angle of the patches, $\theta$ (Fig. 3(d)), were determined for each generation from the TEM images. Fig. 3(e) shows the evolution of $\cos \theta$ with the silica core diameter. The experimental values (red dots) are in a good agreement with those calculated using a geometric model (blue line), based on the space filling between four $135 \mathrm{~nm}$ PS nodules forming a contact angle of $143^{\circ}$ with a central silica core of $53 \mathrm{~nm}$ (see supplementary material). This result confirms the conformational growth of the silica core. Remarkably, a value of $\cos \theta$ as high as 0.91 could be obtained for generation \#8, which corresponds to a regrown silica core of 288 $\mathrm{nm}$ in diameter. This value is required for the spontaneous formation of a diamond crystal phase, as it cannot be achieved by assembly of particles with wider patches [14]. 
(a)

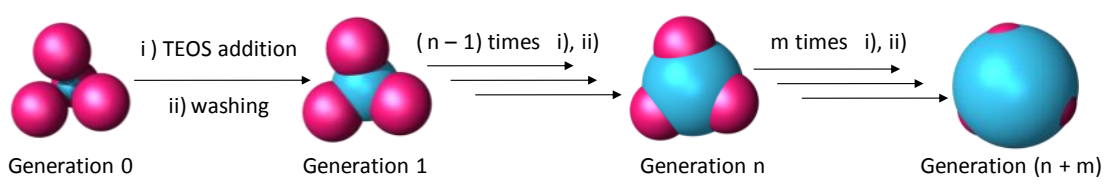

(b)
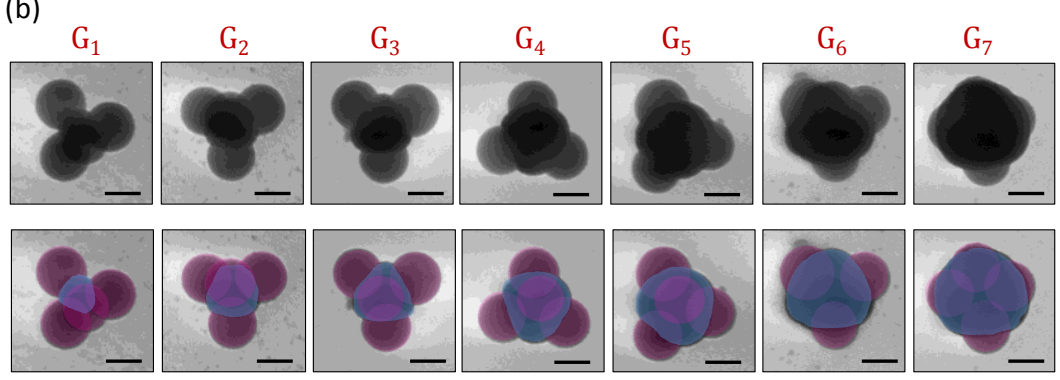

(c)
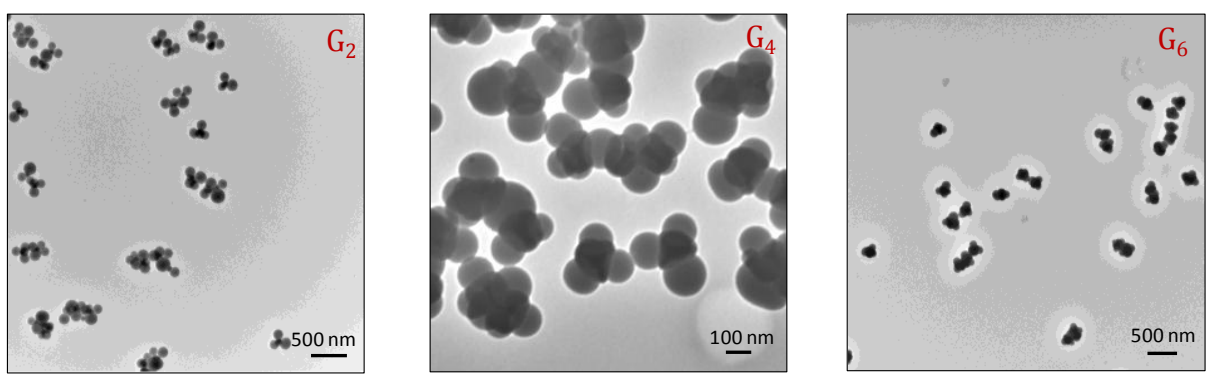

(d)

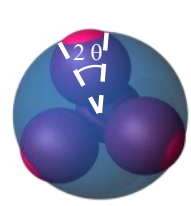

(e)
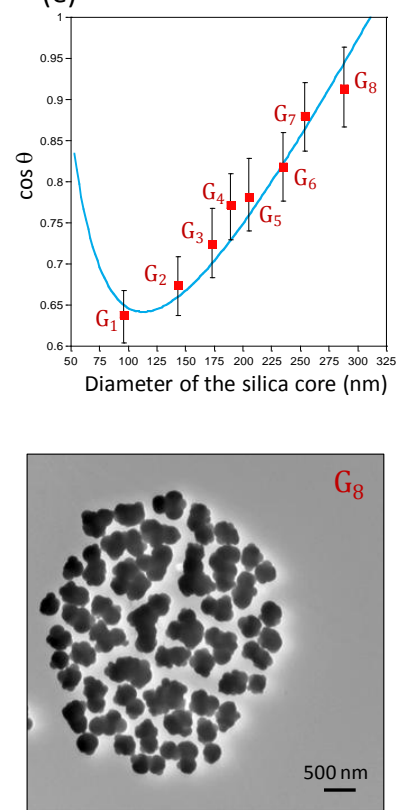

Fig. 3 (a) Synthetic route for the preparation of the tetrahedral patchy particles. (b) TEM images of the particles obtained after 1 to 8 iterative silica growth steps. The bottom rows show colorized images (silica in blue and PS in pink). Scale bars: $100 \mathrm{~nm}$. (c) Low-magnification TEM images of the particles obtained after 2, 4, 6 and 8 silica growth steps. (d) Cartoon showing that the patches size can be characterized by a spherical cone of angular width $2 \theta$; (e) Evolution of $\cos \theta$ with the diameter of the silica core. Errors bars were deduced from the analysis of $\sim 20$ particles for each generation. For the calculation of $\cos \theta$ (blue line), we considered that the PS nodules have an average diameter of $135 \mathrm{~nm}$ and initially form a contact angle of $143^{\circ}$ with a silica core of $53 \mathrm{~nm}$ [24]

The synthesis of NPs with patches of controlled size was further evidenced by EDX experiments. The EDX maps of generations 2, 4, 6 and 8 (Fig. 4) clearly show an enlargement of the silica NP with the number of stages, the silica core progressively encapsulating the PS nodules. 


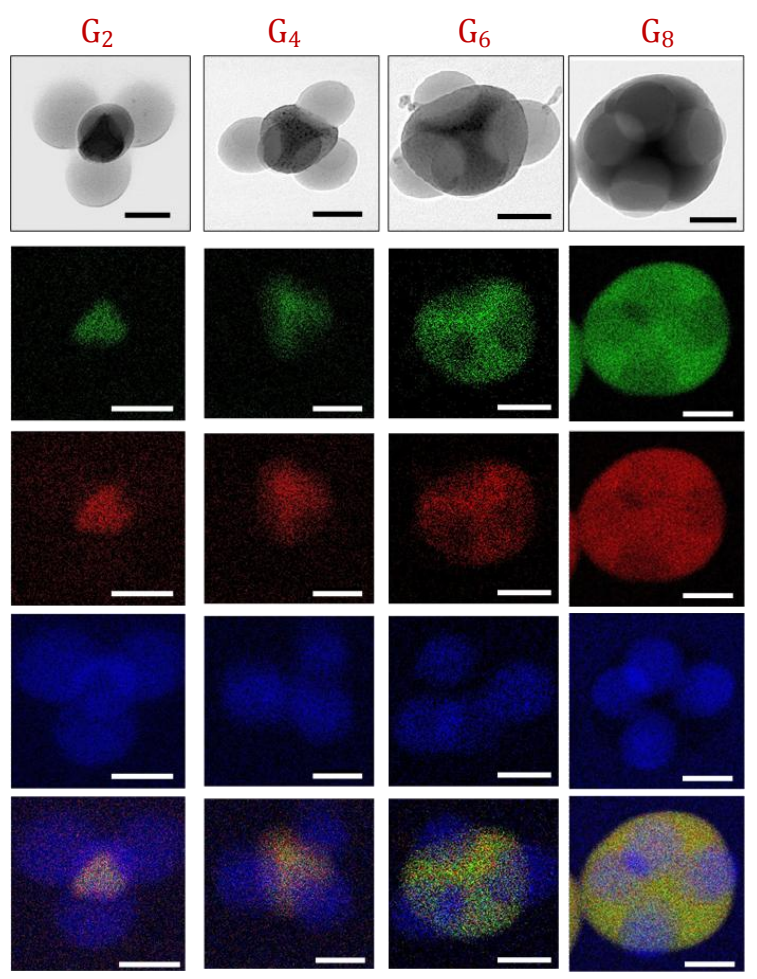

Fig. 4 TEM images and EDX maps of the particles obtained after 2, 4, 6 and 8 generations. The distributions of silicon, oxygen and carbon are colored in green, red and blue, respectively. Scale bars: $100 \mathrm{~nm}$

\section{Conclusions}

In conclusion, silica NPs with four circular PS patches of controlled size with a tetrahedral geometry have been synthesized through the conformational enlargment of the silica core of binary tetrapods. A multi-step process has been developed in order to avoid the undesired formation of silica bumps at the surface of the PS nodules during the silica growth. PS patches characterized by an opening angle as small as $24^{\circ}$ have been obtained. Such a possibility to control not only the position but also the size of the surface patches opens the way to the fabrication of new colloidal clusters or different crystal phases, including the diamond structure [14], by self assembly. For example, the assembly of the patchy silica NPs could be triggered by making their PS patches sticky through incubation in a suitable mixture of a good and a bad solvent for PS [25].

\section{Conflicts of interest}

The authors declare no conflicts of interest.

\section{Funding}


This work was supported by the Agence Nationale de la Recherche (ENLARgER project, ANR-15-CE09-0010), the LabEx AMADEus (ANR-10-LABX-42) and IdEx Bordeaux (ANR-10-IDEX-03-02), that is, the Investissements d'Avenir programme of the French government. R. Khalaf thanks the French Ministry of Higher Education, Research and Innovation and Campus France for her $\mathrm{PhD}$ grant.

\section{Acknowledgements}

STEM EDX experiments were performed at the Plateforme de Caractérisation des Matériaux (UMS 3626, Pessac, France).

\section{References}

[1] Meseguer F (2005) Colloidal crystals as photonic crystals. Colloids Surf. A Physicochem. Eng. Asp. 270271: 1-7. https://doi.org/10.1016/j.colsurfa.2005.05.038

[2] Kim S-H, Lee SY, Yang S-M, Yi G-R (2011) Self-assembled colloidal structures for photonics. NPG Asia Mater 3: 25-33. https://doi.org/10.1038/asiamat.2010.192

[3] Fleischhaker F, Arsenault AC, Kitaev V, Peiris FC, von Freymann G, Manners I, Zentel R, Ozin GA (2005) Photochemically and thermally tunable planar defects in colloidal photonic crystals. J. Am. Chem. Soc. 127: 9318-9319. https://doi.org/10.1021/ja0521573

[4] Fenzl C, Hirsch T, Wolfbeis OS (2014) Photonic crystals for chemical sensing and biosensing. Angew. Chem. Int. Ed. 53: 3318-3335. https://doi.org/10.1002/anie.201307828

[5] Galisteo-López JF, Ibisate M, Sapienza R, Froufe-Pérez LS, Blanco A, López C (2011) Self-assembled photonic structures. Adv. Mater. 23: 30-69. https://doi.org/10.1002/adma.201000356

[6] Shevchenko EV, Talapin DV, Murray CB, O’Brien S (2006) Structural characterization of self-assembled multifunctional binary nanoparticle superlattices. J. Am. Chem. Soc. 128: 3620-3637. https://doi.org/10.1021/ja0564261

[7] Ho KM, Chan CT, Soukoulis CM (1990) Existence of a photonic gap in periodic dielectric structures. Phys. Rev. Lett. 65: 3152-3155. https://doi.org/10.1103/PhysRevLett.65.3152

[8] Maldovan M, Thomas EL (2004) Diamond-structured photonic crystals. Nat. Mater. 3: 593-600. https://doi.org/10.1038/nmat1201

[9] Ngo TT, Liddell CM, Ghebrebrhan M, Joannopoulos JD (2006) Tetrastack: Colloidal diamond-inspired structure with omnidirectional photonic band gap for low refractive index contrast. Appl. Phys. Lett. 88: 241920. https://doi.org/10.1063/1.2206111 
[10] Ducrot E, He M, Yi G-R, Pine DJ (2017) Colloidal alloys with preassembled clusters and spheres. Nat. Mater. 16 : 652-657. https://doi.org/10.1038/nmat4869

[11] Nelson DR (2002) Toward a tetravalent chemistry of colloids. Nano Lett. 2: 1125-1129. https://doi.org/10.1021/n10202096

[12] Doye JPK, Louis AA, Lin I-C, Allen LR, Noya EG, Wilber AW, Kok HC, R. Lyus R (2007) Controlling crystallization and its absence: proteins, colloids and patchy models. Phys. Chem. Chem. Phys. 9: 2197-2205. https://doi.org/10.1039/B614955C

[13] Zhang Z, Keys AS, Chen T, Glotzer SC (2005) Self-assembly of patchy particles into diamond structures through molecular mimicry. Langmuir 21 : 11547-11551. https://doi.org/10.1021/la0513611

[14] Smallenburg F, Sciortino F (2013) Liquids more stable than crystals in particles with limited valence and flexible bonds. Nature Phys. 9: 554-558. https://doi.org/10.1038/nphys2693

[15] Ravaine S, Duguet E (2017) Synthesis and assembly of patchy particles: Recent progress and future prospects. Curr. Opin. Colloid Interface Sci. 30 : 45-53. https://doi.org/10.1016/j.cocis.2017.05.002

[16] Li W, Palis H, Mérindol R, Majimel J, Ravaine S, Duguet E (2020) Colloidal molecules and patchy particles: complementary concepts, synthesis and self-assembly. Chem. Soc. Rev. 49: 1955-1976. https://doi.org/10.1039/C9CS00804G

[17] Perro A, Duguet E, Lambert O, Taveau J-C, Bourgeat-Lami E, Ravaine S (2009) A chemical synthetic route towards "colloidal molecules". Angew. Chem. Int. Ed. 48: 361-365. https://doi.org/10.1002/anie.200802562

[18] Gong Z, Hueckel T, Yi G-R, Sacanna S (2017) Patchy particles made by colloidal fusion. Nature 550: 234238. https://doi.org/10.1038/nature23901

[19] Kraft DJ, Vlug WS, van Kats CM, van Blaaderen A, Imhof A, Kegel WK (2009) Self-Assembly of Colloids with Liquid Protrusions. J. Am. Chem. Soc. 131: 1182-1186. https://doi.org/10.1021/ja8079803

[20] Désert A, Chaduc I, Fouilloux S, Taveau J-C, Lambert O, Lansalot M, Bourgeat-Lami E, Thill A, Spalla O, Ravaine S, Duguet E (2012) High-yield preparation of polystyrene/silica clusters of controlled morphology. Polym. Chem. 3: 1130-1132. https://doi.org/10.1039/C2PY20058A

[21] Désert A, Hubert C, Fu Z, Moulet L, Majimel J, Barboteau P, Thill A, Lansalot M, Bourgeat-Lami E, Duguet E, Ravaine S (2013) Synthesis and site-specific functionalization of tetravalent, hexavalent, and dodecavalent silica particles. Angew. Chem. Int. Ed. 52: 11068-11072. https://doi.org/10.1002/anie.201304273

[22] Hubert C, Chomette C, Rouet P-E, Désert A, Treguer-Delapierre M, Majimel J, Mornet S, Perro A, Duguet E, Ravaine S (2016) Regioselective functionalization of dimpled silica particles. Colloids Surf. A Physicochem. Eng. Asp. 510: 239-244. https://doi.org/10.1016/j.colsurfa.2016.05.089 
[23] Issa AA, Luyt AS (2019) Kinetics of alkoxysilanes and organoalkoxysilanes polymerization: a review. Polymers 11: 537. https://doi.org/10.3390/polym11030537

[24] Taveau J-C, Nguyen D, Perro A, Ravaine S, Duguet E, Lambert O (2008) New insights into the nucleation and growth of PS nodules on silica nanoparticles by 3D cryo-electron tomography. Soft Matter 4: 311-315. https://doi.org/10.1039/B710137F

[25] Li W, Ravaine S, Duguet E (2020) Clustering of asymmetric dumbbell-shaped silica/polystyrene nanoparticles by solvent-induced self-assembly. J. Colloid Interface Sci. 560: 639-648. https://doi.org/10.1016/j.jcis.2019.10.104 